\title{
Schedule at a Glance
}

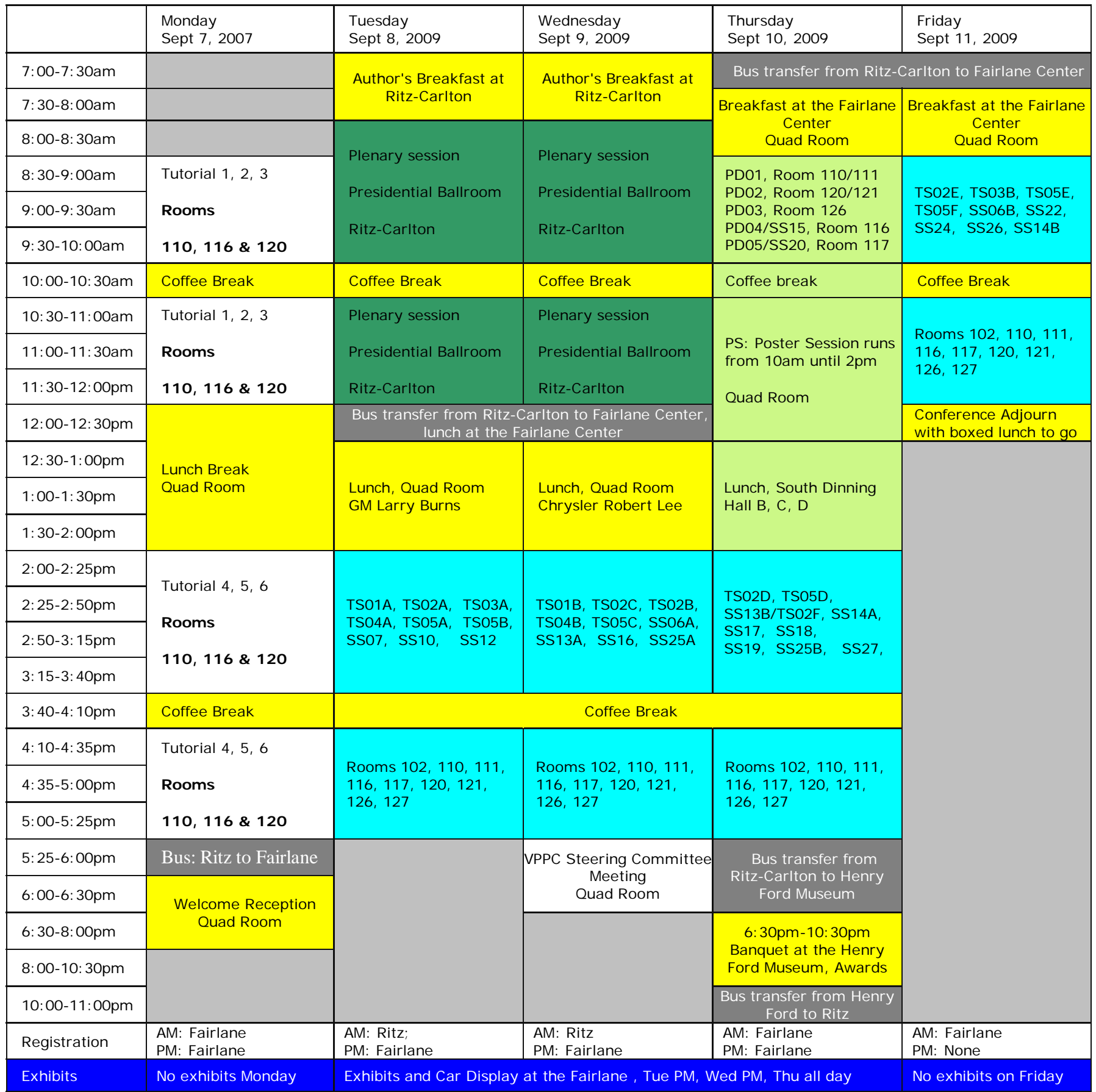

1. Tuesday and Wednesday breakfast and Tuesday and Wednesday morning plenary sessions are held at the Presidential Ballroom, the Ritz-Carlton, 300 Town Center Drive, Dearborn, MI 48126

2. All the rest of the conference are held in the Fairlane Center, University of Michigan-Dearborn, 19000 Hubbard Drive, Dearborn, Michigan 48126 -2638

3. Walking distance from Ritz-Carlton to Fairlane Center-UMD, 0.4 miles, 8 to 15 minutes.

4. Car transportation between Ritz-Carlton and the Fairlane Center is also available from the Hotel car, and from student volunteers upon request during the conference.

\begin{tabular}{|c|c|}
\hline Key: & Color Code: \\
\hline KS - Keynote Session (plenary session) & Dark Blue: plenary sessions at Ritz Carlton \\
\hline TS - Technical Session (regular oral sessions, including TF) & Yellow: meal function, reception \& break refreshments \\
\hline SS - Special Session & Light green: poster session and panel session at Farilane Center \\
\hline TF - Technical Forum & Light blue: parallel oral sessions at the Fairlane Center \\
\hline PD - Panel Discussion & Dark: bus transfer \\
\hline PS - Poster Session & Grey: no activity planned \\
\hline
\end{tabular}

